Article

\title{
Increase in Fast Response Time of the Resistance-to-Voltage Converter When Monitoring the Cable Products' Insulation Resistance
}

\author{
Nikolay I. Yermoshin *(D), Evgeny V. Yakimov, Aleksandr E. Goldshtein and Dmitry A. Sednev \\ School of Non-Destructive Testing, National Research Tomsk Polytechnic University, 30 Lenin Avenue, \\ 634050 Tomsk, Russia; shishkovka@mail.ru (E.V.Y.); algol@tpu.ru (A.E.G.); sednev@tpu.ru (D.A.S.) \\ * Correspondence: nikvan@tpu.ru
}

check for

updates

Citation: Yermoshin, N.I.; Yakimov, E.V.; Goldshtein, A.E.; Sednev, D.A. Increase in Fast Response Time of the Resistance-to-Voltage Converter When Monitoring the Cable Products' Insulation Resistance. Sensors 2021, 21, 368. https://doi.org/10.3390/ s21020368

Received: 27 October 2020 Accepted: 4 January 2021

Published: 7 January 2021

Publisher's Note: MDPI stays neutral with regard to jurisdictional clai$\mathrm{ms}$ in published maps and institutional affiliations.

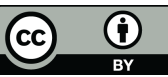

Copyright: (C) 2021 by the authors. Licensee MDPI, Basel, Switzerland. This article is an open access article distributed under the terms and conditions of the Creative Commons Attribution (CC BY) license (https:// creativecommons.org/licenses/by/ $4.0 /)$.
Abstract: Theoretical and experimental studies were conducted to investigate the impact of the cable capacitance during measurements of insulation resistance on the fast response time of a resistance-tovoltage converter. From a comparison of the results of simulation with the data obtained during the experiments, it was determined that the dependence characteristics of the settling time of resistance under measurement on the capacitance are identical to the analogous characteristics of electronic components of the resistance-to-voltage converter. It was experimentally proven that using T-shaped feedback in the resistance-to-voltage converter during the cable insulation resistance measurements reduces the settling time of the data by 1-3 times in comparison with a classical feedback system. Furthermore, when using the optimal parameters, the settling time of the resistance-to-voltage converter with T-shaped feedback depends to a lesser degree on the capacitance of the object under control.

Keywords: resistance-to-voltage converter; cable insulation; insulation resistance; capacitance; electrical resistance measurement; settling time

\section{Introduction}

Cables, cords, and wires represent the most demanded products used in radio engineering, electrical, and electronic equipment. The main characteristic of the quality evaluation of cable insulation is electrical insulation resistance [1,2].

The complete circuit of cable substitution represents the chain with distributed parameters converted to the unit of length: conductor resistance $R_{C}$, inductance $L_{C}$, insulation capacitance $C_{I N S}$, and insulation resistance $R_{I N S}$. Figure 1a demonstrates the equivalent circuit of the cable substitution.

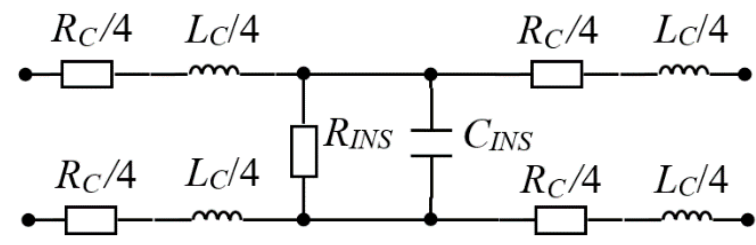

(a)

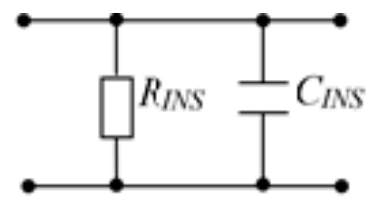

(b)
Figure 1. The circuit of real twin cable substitution: (a) equivalent; (b) simplified.

Inductance and conductor resistance of the cable produce impact only at high frequencies. Direct current or low frequencies are used during insulation resistance measurements. Due to this, the impact of inductance and conductor resistance is neglected during monitoring of insulation resistance of cables. For example, for coaxial cable RG6U [3] the following parameters are given: $R_{C}=23.26 \Omega / \mathrm{km}, R_{I N S}=1 \mathrm{G} \Omega \cdot \mathrm{km}$, and $C_{I N S}=56.8 \mathrm{nF} / \mathrm{km}$. The 
inductance value for cables is not given in the resources, however a formula exists for its calculation [1]:

$$
L_{C}=K+0.2 \cdot \ln \frac{2 S}{d},(\mathrm{mH} / \mathrm{km})
$$

where $K$-constant, for cable RG6U equals $0.05 \mathrm{mH} / \mathrm{km}$; $S$-axial spacing between conductors within the cable ( $\mathrm{mm}$ ), for cable RG6U equals $2.3 \mathrm{~mm}$; $d$ - the conductor diameter (mm), for cable RG6U equals $1.024 \mathrm{~mm}$.

It follows from Formula (1) that inductance of cable RG6U equals $0.35 \mathrm{mH} / \mathrm{km}$. At a frequency of $50 \mathrm{~Hz}$ with a cable length of $1000 \mathrm{~m}$, the total inductance resistance equals $0.11 \Omega$, total insulation capacity resistance is $56.1 \mathrm{k} \Omega$, conductor resistance is $23.26 \Omega$, and insulation resistance is $1 \mathrm{G} \Omega$. Thus, it has been observed that inductance reactance and conductor resistance are significantly less than insulation capacitance reactance and insulation resistance, respectively.

Figure $1 \mathrm{~b}$ demonstrates the simplified circuit of real cable substitution with switched on in-parallel ideal capacitance and conductor resistance. Resistance $R_{I N S}$ characterizes the resistive current component for all of the processes related to energy absorption.

The main problems of measurements of electrical cable insulation resistance pertain to [4-6]:

- the impact of the capacitance of cable products on the fast response time of measurement instruments (teraohmmeters);

- sensitivity of the teraohmmeter output chain to low frequency noise.

In compliance with the standard "UL 2556 Standard for Safety for Wire and Cable Test Methods" [7], the test voltage must be from 100 to $500 \mathrm{~V}$. The value reading for electrical resistance of insulation during measurements is to be conducted after $1 \mathrm{~min}$ because of the momentum of applying the measuring voltage to the sample. The error of measurement should not exceed $10 \%$.

Within the undertaken review, the methods for direct evaluation were considered. Their main advantage is the simplicity of device design and relatively high range of measurement. Among the limitations are low fast response time and the necessity of shielding the object under control to ensure the accuracy of resistance measurements [8-10].

The review of bridge techniques revealed that they are practically not used during monitoring of the cable products' insulation resistance because they possess poor noise immunity and, as a sequence, have a high error of measurement [9,11-13].

Based on the Voltmeter-Ammeter method, a large number of monitoring devices have been developed. However, in most cases, the produced devices have a high measurement error, which either exceeds the acceptable set value $[4,9,14]$ or reaches its boundary value. In addition, the limitations include a high reference voltage in the upper range of measurements, which does not satisfy the standard UL 2556 [7].

The method for charging and discharging capacitors possesses the best fast response time among other existing methods. A sufficient number of algorithms have been developed that enable the determination of the steady-state value of the resistance under measurement at the initial stage of charge (discharge) of the capacitive load. Fluke insulation testers are designed using this method. The best characteristics are possessed by Fluke 1555: the upper range of measurements is up to $2 \mathrm{~T} \Omega$, with an error of $20 \%$ at the reference voltage $10,000 \mathrm{~V}$; the charging rate for capacitive load is $5 \mathrm{~s} / \mu \mathrm{F}$; and the discharge rate for capacitive load is $1.5 \mathrm{~s} / \mu \mathrm{F}$ [15]. The limitations for the cable insulation resistance testers based on this method include the high error of measurement and high reference voltage, which are not in compliance with the standard applied for monitoring cable insulation resistance [7]. A high measurement error of signals results in poor noise immunity of monitoring devices.

Satisfactory noise immunity characterizes the instruments based on the method of converting resistance to voltage. The work [16] describes different variants of noise immune resistance-to-voltage converters, including a study of the converters' fast response time. However, fast response time was assessed only with active resistance components. The 
measuring time for a resistor of $1 \mathrm{~T} \Omega$ was $30 \mathrm{~s}$. Work [17] describes a resistance-to-voltage converter in which the problem of shielding against low frequency noises was solved (less than $1 \mathrm{~Hz}$ ).

Based on the review of the methods of measurement of cable products' insulation resistance, the conclusion can be reached that teraohmmeters based on resistance-to-voltage converter possess the most efficient interference immunity. However, the resources do not contain sufficient information on studies of fast response time of resistance-to-voltage converters during measurements of cable insulation resistance, or on methods to increase their fast response time. Thus, the objective of this research is to study the feasibility of increasing fast response time of resistance-to-voltage converters during measurements of cable insulation resistance.

In this study, the fast response time of a resistance-to-voltage converter was compared with the classical feedback system and the fast response time of a resistance-to-voltage converter with T-shaped feedback during measurements of cable insulation resistance. First, simulation of resistance-to-voltage converter circuits was performed and then experimental testing was conducted.

\section{Materials and Methods}

If using an ideal operational amplifier, the output voltage of the resistance-to-voltage converter equals $[18,19]$ :

$$
U_{O U T(I D)}=-U_{R E F} \cdot \frac{R_{0}}{R_{I N S}}
$$

where $U_{R E F}-\mathrm{DC}$ reference voltage; $R_{0}$-reference resistance.

From Formula (2), it is seen that the greater resistance $R_{0}$ in the feedback loop, the greater resistance can be measured. However, as a rule, the greater the resistor resistance, the lower its accuracy. Therefore, to ensure a small error of the resistance-to-voltage converter, the resistance of the feedback should be selected to have the lowest nominal value possible (less than $1 \mathrm{G} \Omega$ ). For example, high voltage resistors from Riedon HVS Series within the range from 1 to $100 \mathrm{G} \Omega$ have an error of $1-2 \%$, whereas within the range from $1 \mathrm{M} \Omega$ to $1 \mathrm{G} \Omega$, the error is $0.25-0.5 \%$, which is 4 times less [20].

Using T-shaped feedback to obtain a stable useful signal requires resistors with lesser nominal characteristics, which theoretically allow reduction of the settling time for the output signal of the resistance-to-voltage converter and, accordingly, increase its fast response time. Figure 2 demonstrates the basic resistance-to-voltage converter.

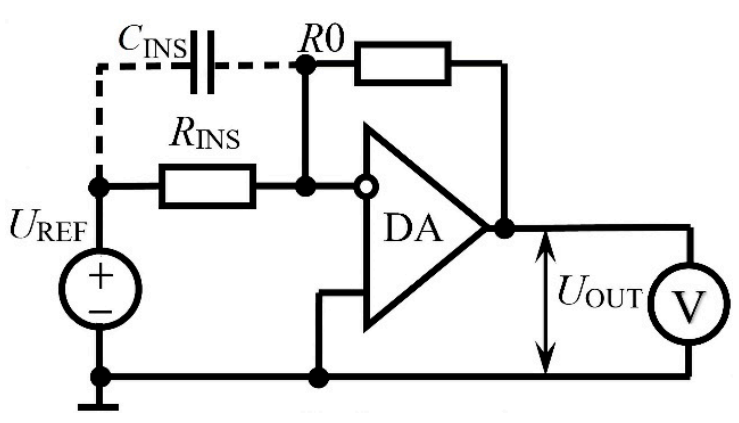

(a)

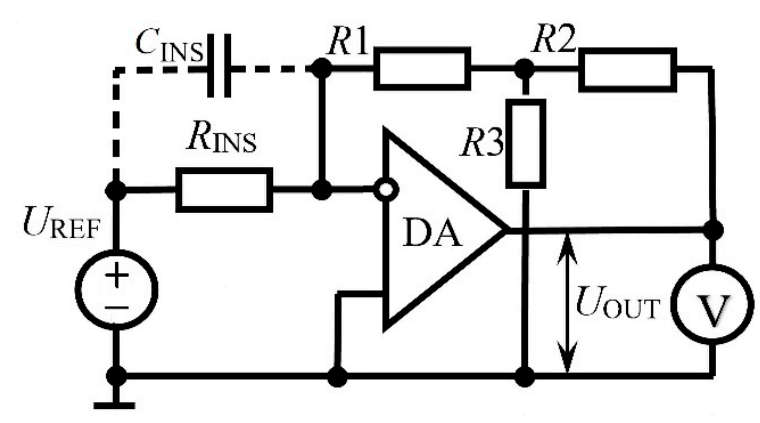

(b)

Figure 2. General scheme of the resistance-to-voltage converter (a) with a classical feedback system (b) with T-shaped feedback: $R_{1}, R_{2}$ and $R_{3}$ are resistances of T-shaped feedback; $D A$-operational amplifier; $V$-voltmeter.

In the case in which the operational amplifier does not possess a saturation mode, then, in the teraohmmeter designed based on the circuit presented in Figure 2, theoretically, the settling time of the data practically does not depend on the electrical capacitance of the cable because the object under study is under direct current voltage from the source with low output resistance $R_{S O U}$. Under $R_{S O U}=10 \Omega$ and capacitance $C_{I N S}=56.8 \mathrm{nF}$, the time 
constant for the capacitor charge equals $568 \times 10^{-9} \mathrm{~s}$. A detailed examination of this circuit shows that a comparatively high capacitance $C_{I N S}$ forms a differentiator amplifier. With the reference voltage placed on the resistance under study, high output voltage will tend to be formed on the converter output and the amplifier will transit to the saturation mode. The common mode is set during a long period of time, during which the cable capacitance charge occurs via reference resistance $R_{0}$ and input resistance of the operational amplifier. Figure 3 demonstrates the behavior of the transition process with the reference voltage placed on the resistance under study.

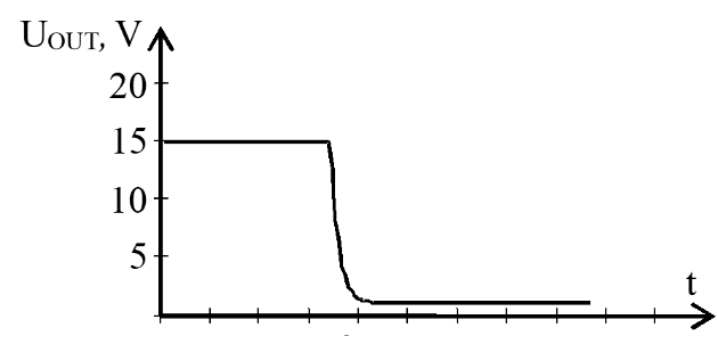

Figure 3. The transition process when switching on the teraohmmeter based on resistance-to-voltage converter.

The transfer equation for the resistance-to-voltage converter with T-shaped feedback, using an ideal operational amplifier, is described with the expression $[19,20]$ :

$$
U_{O U T(I D)}=-U_{R E F} \cdot \frac{R_{1}+R_{2}+\frac{R_{1} \cdot R_{2}}{R_{3}}}{R_{I N S}}=-U_{R E F} \cdot \frac{R_{E Q}}{R_{I N S}},
$$

where $R_{E Q}$-equivalent resistance of T-shaped feedback.

Equation (3) does not take into consideration many operational amplifier parameters (input voltage and current, zero offset voltage, target amplification coefficient, electrostatic protection, and others) which restrict the application of T-shaped feedback to the design of the resistance-to-voltage converter. In the work [20], using simulations and further proved in experiments, it was determined that the output voltage of the converter with T-shaped feedback $U_{\text {OUT }}$ does not depend on the combination of resistance $R_{2}$ and $R_{3}$, under the condition that they provide the same equivalent resistance $R_{E Q}$. However, no explanation was provided for the useful signal bias of the output voltage caused by the significant decrease of the nominal resistance $R_{1}$ in relation to $R_{E Q}$. Further research has revealed the decrease in the reference resistance $R_{1}$ in relation to $R_{E Q}$ in multiples of increases in the voltage of the useful signal bias of the operational amplifier $\left(R_{3}\right.$ is too small in relation to $R_{1}$ and its value can be neglected). The statement is expressed by the following formula:

$$
U_{\text {OUT.OF }}=\frac{R_{E Q}}{\left(R_{1}+R_{3}\right)} \cdot U_{O F},
$$

where $U_{O U T} \cdot \mathrm{OF}$ - offset of the output voltage of the resistance-to-voltage converter with T-shaped feedback; $U_{O F}-$ offset voltage of the operational amplifier.

It is worth mentioning that Equation (4) does not consider all of the parameters of the operational amplifier, but only that which most significantly impacts the useful signal bias of the resistance-to-voltage converter.

To design the resistance-to-voltage converter with T-shaped feedback, it is necessary to use an operational amplifier with low offset voltage as the input operational amplifier. From a literature review [21,22], the most suitable variant of the operational amplifier is ADA4530-1, which combines low input current and low offset voltage (Table 1). This operational amplifier was used in all of the experiments. 
Table 1. The main characteristics of operational amplifiers with low input current.

\begin{tabular}{|c|c|c|c|c|c|c|c|}
\hline Operational Amplifier & $I_{I N}, \mathbf{f A}^{1}$ & $U_{O F}, \mu \mathrm{V}^{2}$ & $R_{I N}, \mathrm{~T} \Omega^{3}$ & $C_{I N}, \mathrm{pF}^{4}$ & $u_{S U P}, \mathbf{V}^{5}$ & $G B P, \mathrm{MHz}^{6}$ & $A_{D}{ }^{7}$ \\
\hline AD549L & \pm 60 & \pm 500 & 1000 & 0,8 & \pm 15 & 1 & $>0.1 \times 10^{6}$ \\
\hline ADA4530-1 & \pm 20 & \pm 40 & $>100$ & 8 & \pm 8 & 2 & $>3.16 \times 10^{6}$ \\
\hline LTC6268 & \pm 20 & \pm 700 & $>1$ & 0,1 & +5 & 4000 & $>0.125 \times 10^{6}$ \\
\hline OPA128LM & \pm 75 & \pm 500 & 1000 & 2 & +15 & 1 & $>3.16 \times 10^{5}$ \\
\hline LMP7721 & \pm 20 & \pm 150 & $>1$ & 15 & +5 & 15 & $>40 \times 10^{3}$ \\
\hline
\end{tabular}

${ }^{1}$ Input current of operational amplifier; ${ }^{2}$ Offset voltage of operational amplifier; ${ }^{3}$ Input resistance of operational amplifier; ${ }^{4}$ Input capacity of operational amplifier; ${ }^{5}$ Power supply voltage of operational amplifier; ${ }^{6}$ Gain bandwidth product; ${ }^{7}$ Open loop gain.

Using T-shaped feedback with the ADA4530-1 operational amplifier allows the nominal reference resistance to be decreased by at least 100 times, which, with the useful signal in $1 \mathrm{~V}$, results in an error in the signal offset of not more than $0.4 \%$; thus, the offset voltage of the ADA4530-1 operational amplifier is not more than $40 \mu \mathrm{V}$ [21]. Under higher correlation, the error of measurement increases and the output signal of the converter starts to converge to the power supply voltage of the operational amplifier.

Figure 4 represents the electrical circuit of the resistance-to-voltage converter under study.

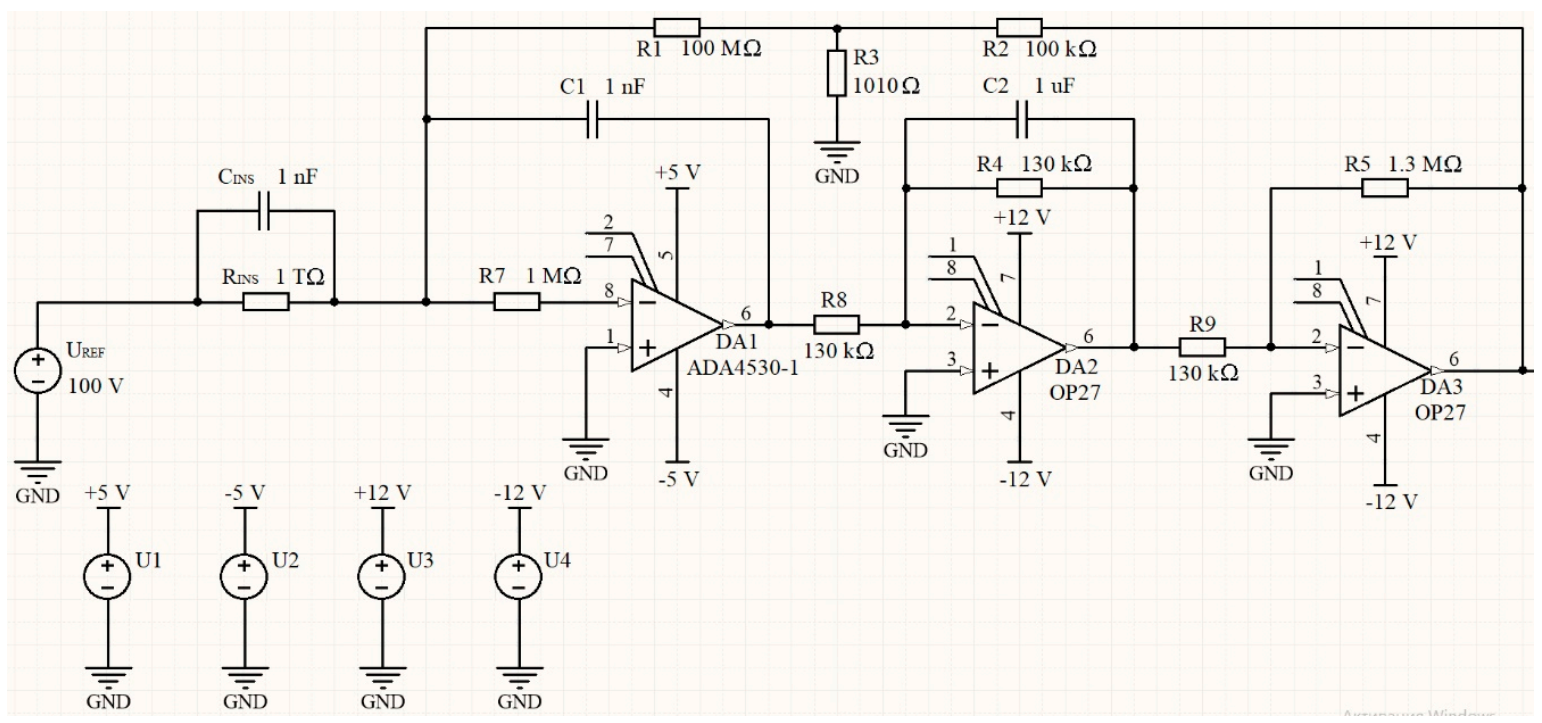

Figure 4. The electrical circuit of the resistance-to-voltage converter under study in the electrical circuit design software Altium Designer.

The converter comprises three cascades with the common negative feedback: amplifier integrator $D A_{1}$, low-pass filter based on amplifier $D A_{2}$, and direct-current amplifier $D A_{3}$.

Amplifier transmission coefficient $D A_{3}$ is described in the equation:

$$
K_{3}=-\frac{R_{5}}{R_{9}},
$$

For the amplifier $D A_{3}$ the coefficient $K_{3}=-10\left(R_{9}=130 \mathrm{k} \Omega, R_{5}=1.3 \mathrm{M} \Omega\right)$.

Frequency response for low-pass filter is expressed in the formula:

$$
K_{2}(j \cdot \omega)=-\frac{R_{4}}{R_{8}} \cdot \frac{1}{1+j \cdot \omega \cdot R_{4} \cdot C_{2}},
$$

For the circuit discussed $R_{8}=130 \mathrm{k} \Omega, R_{4}=130 \mathrm{k} \Omega, C_{2}=1 \mu \mathrm{F}$. 
Thus, the frequency response for the combined three cascaded resistance-to-voltage converters is described with the second-order equation:

$$
K(j \cdot \omega)=-\frac{R_{E Q}}{R_{I N S}} \cdot \frac{1}{1+j \cdot \omega \cdot b_{1}+(j \cdot \omega)^{2} \cdot b_{2}},
$$

where $b_{1}=C_{1} \cdot R_{E Q} \cdot \frac{R_{8}}{R_{4}} \cdot \frac{1}{K_{3}} ; b_{2}=C_{1} \cdot R_{E Q} \cdot C_{2} \cdot R_{4} \cdot \frac{R_{8}}{R_{4}} \cdot \frac{1}{K_{3}}$.

For the operating current $J_{X}$, set by resistance $R_{I N S}$ under measurement, and the reference voltage $U_{R E F}$, frequency response will be expressed in a similar way, with the exception of resistance $R_{I N S}$ which is not present in the formula:

$$
J_{X}(j \cdot \omega)=-R_{0} \cdot \frac{1}{1+j \cdot \omega \cdot b_{1}+(j \cdot \omega)^{2} \cdot b_{2}},
$$

Coefficients of the frequency response of the teraohmmeter amplifier depend solely on the circuit parameters.

Under equivalent (reference) resistance $R_{E Q}=10 \mathrm{G} \Omega$, capacitance $C_{1}=1 \mathrm{nF}$ and the parameters stated above of the circuit elements, the coefficients equal $b_{1}=1.0, b_{2}=0.13$. At these values, the coefficient of noise attenuation at the frequency of $50 \mathrm{~Hz}$ equals $82.16 \mathrm{~dB}$, and the transient response is $2.7 \mathrm{~s}$.

\section{Results}

3.1. Theoretical Studies of Fast Response Time of the Resistance-to-Voltage Converter with T-Shaped Feedback

To perform initial measurements of the fast response time of the resistance-to-voltage converter with T-shaped feedback, it is necessary to simulate the process of the measurement of insulation resistance for cable products in the electronic circuit design software Altium Designer.

As measurable values, it is necessary to take the reference characteristics of cables that are currently produced. Submarine coaxial cables possess the maximum acceptable insulation resistance ( $50 \mathrm{G} \Omega \cdot \mathrm{km})$, in addition to relatively high electric capacitance $(100 \mathrm{nF} / \mathrm{km})$ (Table 2) [23-27]. Correspondingly, the time constant for such cables can reach up to $5000 \mathrm{~s}$. This correlation of the values of insulation resistance and electrical capacitance of cable will be selected as maximum acceptable value.

Noise immunity and fast response time of the resistance-to-voltage converter presented in Figure 4 depends, first, on the value of capacitor $C_{1}$ in the integrator. With insufficient capacitor $C_{1}$ capacitance, the level of noise in the converter increases and the $D A_{1}$ operational amplifier converges to saturation, which leads to non-operability of the converter. Thus, it is necessary to select the optimal value for the capacitor $C_{1}$ capacitance that allows converter operability in conjunction with its maximum fast response time.

During experiments of actual submarine coaxial cables of different lengths $l$, it is easier to use simulation of resistance $R_{I N S}$ and capacitance $C_{I N S}$ by resistors and capacitors:

(1) $R_{I N S}$ not less $500 \mathrm{G} \Omega$ and $C_{I N S}$ less $10 \mathrm{nF}$ when $l=100 \mathrm{~m}$.

(2) $R_{I N S}$ not less $50 \mathrm{G} \Omega$ and $C_{I N S}$ less $100 \mathrm{nF}$ when $l=1000 \mathrm{~m}$.

(3) $R_{I N S}$ not less $5 \mathrm{G} \Omega$ and $C_{I N S}$ less $1000 \mathrm{nF}$ when $l=10,000 \mathrm{~m}$.

In all of the experiments the resistance of feedback was chosen in such a way that the output voltage $U_{\text {OUT }}$ within the measurable range was equal to $1 \mathrm{~V}$. Resistance values of T-shaped feedback were chosen in accordance with the conclusions (recommendations) obtained in the work [20]. The transient response was understood as the time $T_{S}$, after which the difference of the current value of transient response from the steady-state value of resistance was $5 \%$. 
Table 2. Reference characteristics of cables.

\begin{tabular}{|c|c|c|c|}
\hline Cable Type & $R_{I N S}$ Not Less, G $\Omega \cdot \mathbf{k m}$ & $C_{I N S}$ Less, $\mathrm{nF} / \mathrm{km}$ & Nominal Voltage, $\mathrm{kV}$ \\
\hline $\begin{array}{l}\text { Submarine coaxial cable (PE core insulation, } \\
\text { PE outer sheath) }\end{array}$ & 50 & 100 & 3.5 \\
\hline $\begin{array}{l}\text { Instrumentation cable (polyethylene (PE) core } \\
\text { insulation, pairs individually foiled, Polyvinyl } \\
\text { chloride (PVC) outer sheath) }\end{array}$ & 2 & 370 & 0.3 \\
\hline $\begin{array}{l}\text { Instrumentation cable (PVC, } \\
\text { overall screened, unarmored) }\end{array}$ & 25 & 450 & $0.3 / 0.5$ \\
\hline $\begin{array}{c}\text { Data transmission cable (PE core insulation, } \\
\text { PVC outer sheath) }\end{array}$ & 10 & 52 & 0.15 \\
\hline Cable for drag chains, halogen-free & 0.1 & 60 & 0.3 \\
\hline $\begin{array}{l}\text { Cross-linked polyethylene (XLPE) insulated } \\
\text { and PVC sheathed power cables }\end{array}$ & 0.1 & 800 & $0.6 / 1.0$ \\
\hline $\begin{array}{l}\text { Intrinsically safe cables (Sheathing PVC of high } \\
\text { oxygen index is UV radiation and weather } \\
\text { resistant, is self-extinguishing and } \\
\text { flame retardant) }\end{array}$ & 0.02 & 140 & $0.6 / 1.0$ \\
\hline $\begin{array}{l}\text { Local area network cables (PE core insulation, } \\
\text { PVC outer sheath) }\end{array}$ & 5 & 50 & 0.15 \\
\hline $\begin{array}{c}\text { Coaxial television cable (PE core insulation, } \\
\text { PVC outer sheath) }\end{array}$ & 10 & 67 & 3.5 \\
\hline PVC insulated and sheathed cables & 0.02 & 200 & $0.6 / 1.0$ \\
\hline
\end{tabular}

Figure 5 demonstrates the results of the simulation of dependence of the settling time of resistance under measurement on capacitance $C_{I N S}$, when $C_{1}=1 \mathrm{nF}$ and measurable resistance is $1 \mathrm{~T} \Omega$ and $100 \mathrm{G} \Omega$. During measurements of resistance of $10 \mathrm{G} \Omega$, the output voltage of the resistance-to-voltage converter was not set for the whole range of the capacitance $C_{I N S}$ under study using the converter with a classical feedback system of the operational amplifier, whereas the converter with T-shaped feedback proved to be operable only with the capacitance $C_{I N S}$ of not more than $100 \mathrm{nF}$. At this value, settling of the output voltage was performed with reregulation of the transient response of more than $100 \%$ (Figure 6). Based on this, it is possible to conclude that, in this configuration, the resistance-to-voltage converter possesses a small stability margin on the range of measurements of $10 \mathrm{G} \Omega$. In the range of measurements of $100 \mathrm{G} \Omega$, settling of the output voltage also occurred with reregulation of the transient response of more than $100 \%$, however, a shorter time for reregulation was required, and, correspondingly, a greater stability margin was achieved. In the range of measurements of $1 \mathrm{~T} \Omega$, the settling of the output voltage was monotonous without reregulation.

Based on the obtained dependencies, the advantages of the resistance-to-voltage converter with T-shaped feedback are evident:

- the settling time depends to a lesser degree on the capacitive component of the object under control, and at the range of measurements of $1 \mathrm{~T} \Omega$ it has practically a steady-state value (about $10 \mathrm{~s}$ ) within the whole capacitance range under study;

- fast response time is 1.5-6 times better, depending on the range of measurements of resistance and capacitance value. 


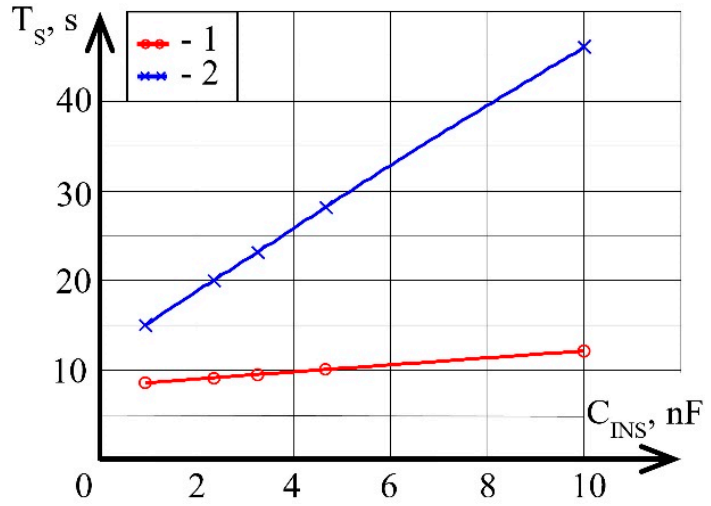

(a)

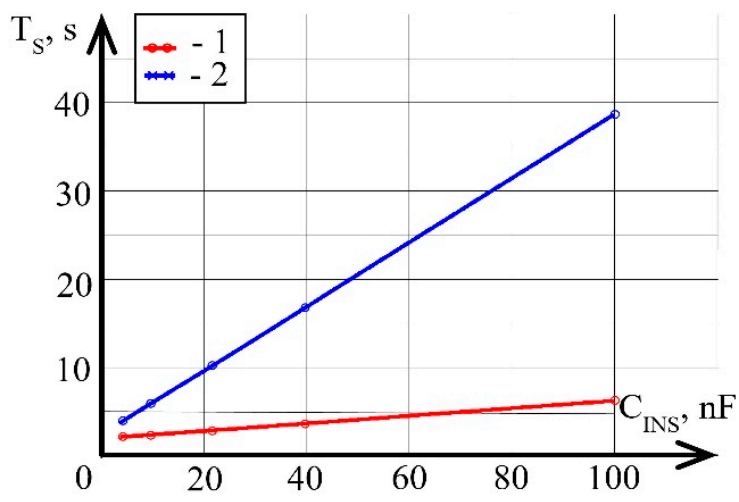

(b)

Figure 5. Theoretical dependences of the settling time during the measurements of insulation resistance on capacitance $C_{I N S}\left(C_{1}=1 \mathrm{nF}, U_{R E F}=100 \mathrm{~V}\right)(\mathbf{a})$ when $R_{I N S}=1 \mathrm{~T} \Omega$ : 1 - the resistance-to-voltage converter with T-shaped feedback with $R_{E Q}=10 \mathrm{G} \Omega\left(R_{1}=100 \mathrm{M} \Omega, R_{2}=100 \mathrm{k} \Omega, R_{3}=1010 \Omega\right) ; 2$ - the resistance-to-voltage converter with a classical feedback system with $R_{E Q}=10 \mathrm{G} \Omega$; (b) when $R_{I N S}=100 \mathrm{G} \Omega$ : 1 - the resistance-to-voltage converter with T-shaped feedback with $R_{E Q}=1 \mathrm{G} \Omega\left(R_{1}=10 \mathrm{M} \Omega, R_{2}=100 \mathrm{k} \Omega, R_{3}=1010 \Omega\right) ; 2$-the resistance-to-voltage converter with a classical feedback system with $R_{E Q}=1 \mathrm{G} \Omega$.

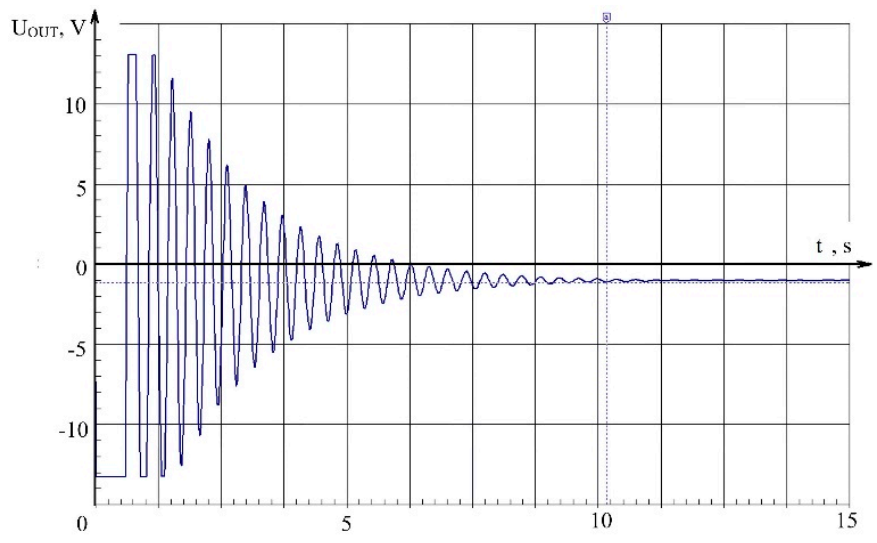

Figure 6. The transient response of the output voltage of the resistance-to-voltage converter with T-shaped feedback $\left(R_{1}=1 \mathrm{M} \Omega, R_{2}=100 \mathrm{k} \Omega, R_{3}=1010 \Omega, R_{E Q}=0.1 \mathrm{G} \Omega, R_{I N S}=10 \mathrm{G} \Omega, C_{I N S}=100 \mathrm{nF}\right.$, $\left.C_{1}=1 \mathrm{nF}, U_{R E F}=100 \mathrm{~V}\right)$.

It is also worth mentioning that, using the resistance-to-voltage converter with this configuration, the settling time depends on the capacitance within the range under study, in compliance with the linear law.

Figure 7 demonstrates the simulation results of dependence of the settling time of resistance under measurement on capacitance $C_{I N S}$, when $C_{1}=10 \mathrm{nF}$.

The resistance-to-voltage converter was demonstrated to be operable within all the ranges of resistance measurements under study.

When measuring the resistance of $1 \mathrm{~T} \Omega$, the settling time of the output voltage was monotonous without reregulation. However, due to the increase in the integrator capacitance, the fast response time significantly decreased. In addition, the settling time for the resistance under measurement was more than $90 \mathrm{~s}$ for both variants of the resistance-tovoltage converters. This is not acceptable in accordance to [7], from which the reading is to take place within $60 \mathrm{~s}$. The characteristic of dependences was linear. 


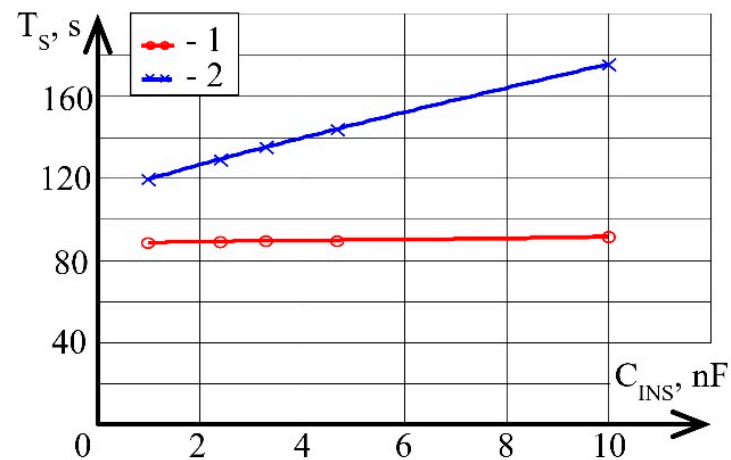

(a)

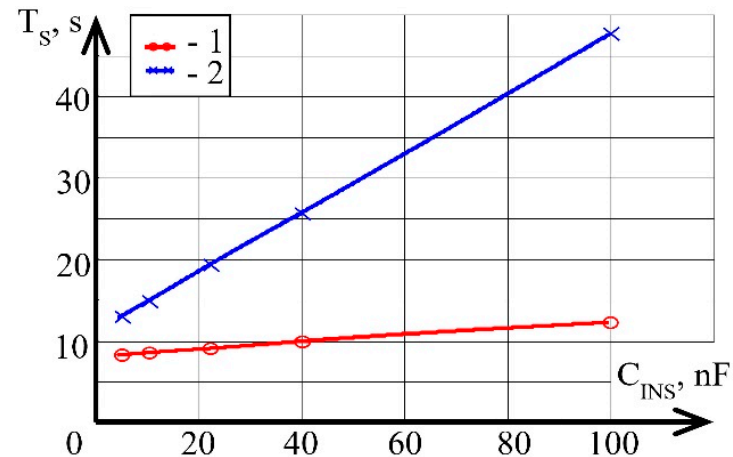

(b)

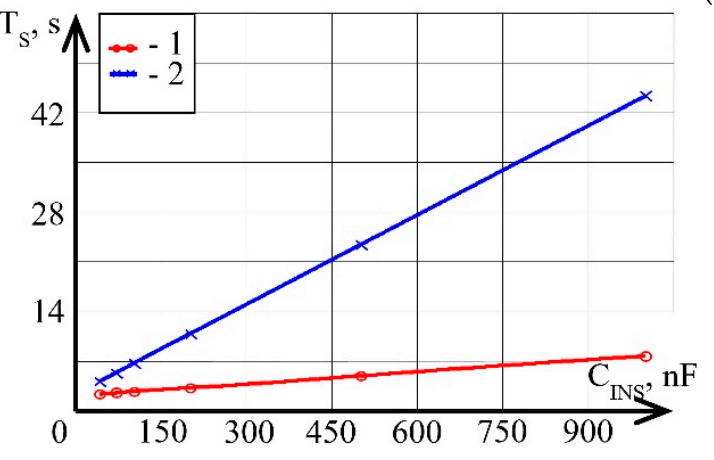

(c)

Figure 7. Theoretical dependences of the settling time during insulation resistance measurements on capacitance $C_{I N S}$ $\left(C_{1}=10 \mathrm{nF}, U_{R E F}=100 \mathrm{~V}\right)(\mathrm{a})$ when $R_{I N S}=1 \mathrm{~T} \Omega: 1$ - the resistance-to-voltage converter with T-shaped feedback with $R_{E Q}=10 \mathrm{G} \Omega\left(R_{1}=100 \mathrm{M} \Omega, R_{2}=100 \mathrm{k} \Omega, R_{3}=1010 \Omega\right) ; 2$ - the resistance-to-voltage converter with a classical feedback system with $R_{E Q}=10 \mathrm{G} \Omega$; (b) when $R_{I N S}=100 \mathrm{G} \Omega$ : 1 一the resistance-to-voltage converter with T-shaped feedback with $R_{E Q}=1 \mathrm{G} \Omega\left(R_{1}=10 \mathrm{M} \Omega, R_{2}=100 \mathrm{k} \Omega, R_{3}=1010 \Omega\right) ; 2$-the resistance-to-voltage converter with a classical feedback system with $R_{E Q}=1 \mathrm{G} \Omega$; (c) when $R_{I N S}=10 \mathrm{G} \Omega$ : 1 一the resistance-to-voltage converter with T-shaped feedback with $R_{E Q}=0.1 \mathrm{G} \Omega\left(R_{1}=1 \mathrm{M} \Omega, R_{2}=100 \mathrm{k} \Omega, R_{3}=1010 \Omega\right) ; 2$ - the resistance-to-voltage converter with a classical feedback system with $R_{E Q}=0.1 \mathrm{G} \Omega$.

At the range of measurements of $100 \mathrm{G} \Omega$, the settling of the output voltage was performed monotonously without reregulating. The fast response time did not change significantly for the resistance-to-voltage converter with a classical feedback system or the resistance-to-voltage converter with T-shaped feedback. The characteristic of dependences was linear.

At the range of measurements of $10 \mathrm{G} \Omega$, the settling of the output voltage was performed with reregulation of the transient response of more than $100 \%$. The fast response time of the resistance-to-voltage converter with T-shaped feedback was demonstrated to be 1.5- 6 times better than that of the resistance-to-voltage converter with a classical feedback system.

With increase in the capacitance value $C_{1}$ in the integrator up to $100 \mathrm{nF}$, the settling time of the resistance under measurement $(1 \mathrm{~T} \Omega$ and $100 \mathrm{G} \Omega)$ on the capacitance increased to $60 \mathrm{~s}$. However, during the resistance measurements of $10 \mathrm{G} \Omega$, the settling time was no more than $14 \mathrm{~s}$ for the resistance-to-voltage converter with T-shaped feedback and no more than $55 \mathrm{~s}$ for the resistance-to-voltage converter with a classical feedback system (Figure 8). 


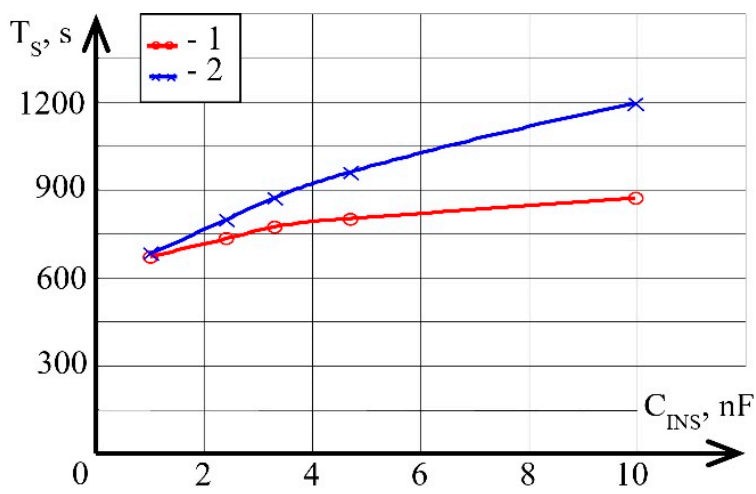

(a)

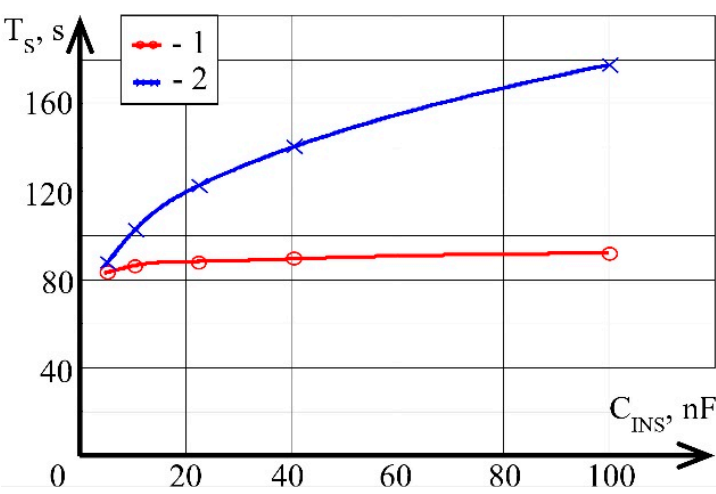

(b)

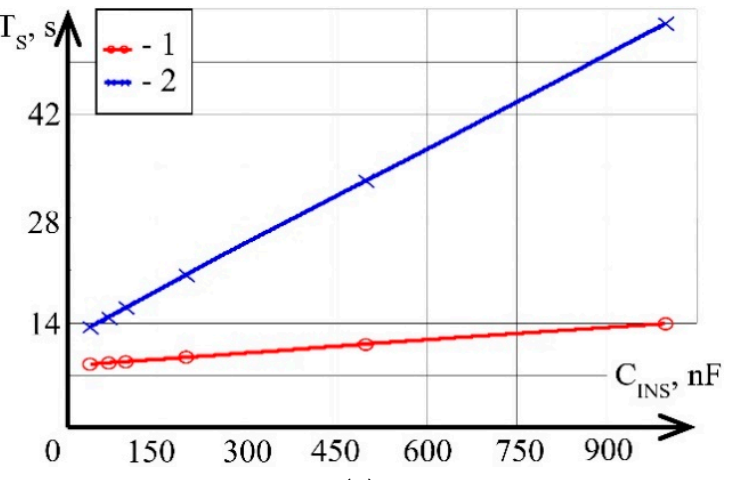

(c)

Figure 8. Theoretical dependencies of the settling time during insulation resistance measurements on capacitance $C_{I N S}$ $\left(C_{1}=100 \mathrm{nF}, U_{R E F}=100 \mathrm{~V}\right)(\mathbf{a})$ when $R_{I N S}=1 \mathrm{~T} \Omega$ : 1 -the resistance-to-voltage converter with T-shaped feedback with $R_{E Q}=10 \mathrm{G} \Omega\left(R_{1}=100 \mathrm{M} \Omega, R_{2}=100 \mathrm{k} \Omega, R_{3}=1010 \Omega\right) ; 2$ - the resistance-to-voltage converter with a classical feedback system with $R_{E Q}=10 \mathrm{G} \Omega$; (b) when $R_{I N S}=100 \mathrm{G} \Omega$ : 1 — the resistance-to-voltage converter with T-shaped feedback with $R_{E Q}=1 \mathrm{G} \Omega\left(R_{1}=10 \mathrm{M} \Omega, R_{2}=100 \mathrm{k} \Omega, R_{3}=1010 \Omega\right) ; 2$-the resistance-to-voltage converter with a classical feedback system with $R_{E Q}=1 \mathrm{G} \Omega$; (c) when $R_{I N S}=10 \mathrm{G} \Omega$ : 1 -the resistance-to-voltage converter with T-shaped feedback with $R_{E Q}=0.1 \mathrm{G} \Omega\left(R_{1}=1 \mathrm{M} \Omega, R_{2}=100 \mathrm{k} \Omega, R_{3}=1010 \Omega\right) ; 2$-the resistance-to-voltage converter with a classical feedback system with $R_{E Q}=0.1 \mathrm{G} \Omega$.

3.2. Experimental Studies of Fast Response Time of the Resistance-to-Voltage Converter with T-Shaped Feedback

Experimental studies were conducted to verify the results obtained during the simulation of the data on the fast response time of the resistance-to-voltage converter with T-shaped feedback when monitoring large resistance values which possess a capacitive component.

In the experimental set-up, the assembly of the elements of the resistance-to-voltage converter was performed on a polytetrafluorethylene plate. This material was chosen due to its great resistivity (about $10^{18} \Omega \cdot \mathrm{m}$ ), which allowed minimization of leakage currents [28].

All studies were performed in a shielding cell (Figure 9), which allowed for minimization of the impact of external noise and fair treatment of the obtained experimental results.

3.2.1. The Usage of the Simplified Circuit of the Cable Substitution as the Object of Measurements

Simulation of the insulation material with the determined properties was performed by simultaneously connecting the KVM resistor (resistor type: composite, vacuum) and K71-7 capacitor (polypropylene film, metalized, single-layer) (Figure 10) [29,30]. Their specifications are given in Table 3. 


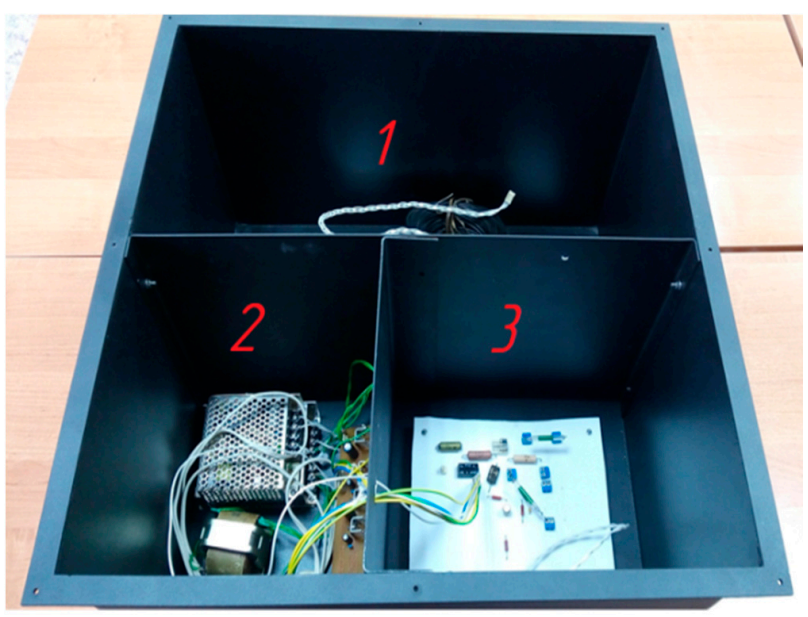

Figure 9. The shielding cell: 1—cell designated for cable allocation; 2-power supply; 3-the resistance-to-voltage converter.

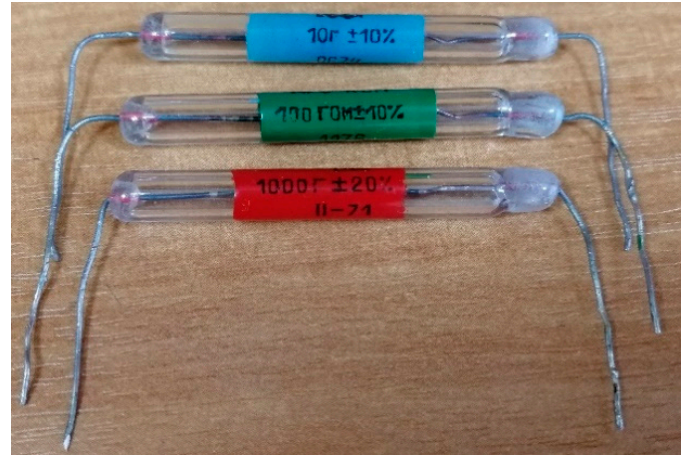

(a)

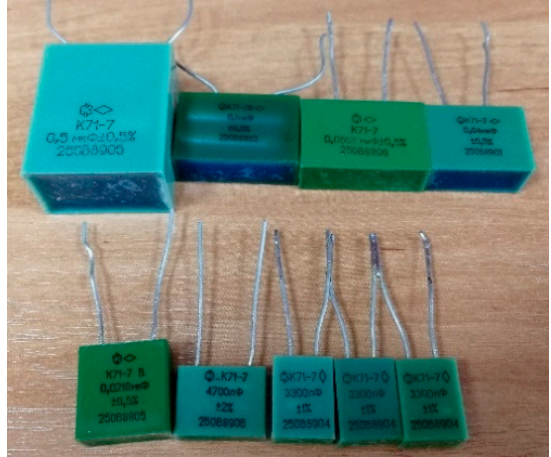

(b)

Figure 10. Appearance of (a) KVM type resistor (b) K71-7 type capacitor.

Table 3. The specifications of KVM resistor and K71-7 capacitor.

\begin{tabular}{ccc}
\hline Specification Name & K71-7 & KVM \\
\hline Nominal voltage & $250 \mathrm{~V}$ & $100 \mathrm{~V}$ \\
Insulation resistance lead-lead, not less & $50 \mathrm{G} \Omega$ & - \\
Insulation resistance lead-sheath, not less & $70 \mathrm{G} \Omega$ & - \\
Loss tangent, not exceeding & 0.001 & - \\
Permissible error of nominal value & $\pm 0.5 \%, \pm 1 \%, \pm 2 \%$ & $\pm 10 \%, \pm 20 \%$ \\
\hline
\end{tabular}

As can be seen from Table 3, the stated insulation resistance of the K71-7 lead-lead capacitor is not less than $50 \mathrm{G} \Omega$, which is comparable with nominal values of the resistances $R_{I N S}$ under study and can impact the measurement results. It is worth mentioning that the specifications for capacitors state the minimum acceptable insulation resistance, while in practice it is significantly greater. During the experiments, comparison of the steady-state value of the output voltage of the resistance-to-voltage converter was undertaken when measuring $R_{I N S}$ resistance with and without connecting $C_{I N S}$. The data of the output voltage of the resistance-to-voltage converter was identical. This means that the insulation resistance of the K71-7 lead-lead capacitor is an order of magnitude greater than $1 \mathrm{~T} \Omega$.

The values of the resistance and capacitances were chosen to be analogous to the theoretical studies. The basic electronic circuit of the resistance-to-voltage converter is presented in Figure 4.

Measurements of the settling time of the transient response of the output voltage of the resistance-to-voltage converter were performed with a digital oscilloscope ADS-5304, 
which allowed long-term data recording to be undertaken. The detailed specifications for the oscilloscope are provided in the work [31].

Figure 11 demonstrates the experimental dependences of the settling time of resistance under measurement on capacitance $C_{I N S}$, when $C_{1}=1 \mathrm{nF}$, and resistance under measurement of $1 \mathrm{~T} \Omega$. When $C_{I N S}$ exceeds $3.3 \mathrm{nF}$ for the resistance-to-voltage converter with a classical feedback system, and when $C_{I N S}$ exceeds $4.7 \mathrm{nF}$ for the resistance-to-voltage converter with T-shaped feedback, due to insufficient capacitance in the integrator of the converter, even under monotonous settling of the transient response of output voltage, spontaneous signal steps appear that do not attenuate at a later time and significantly increase the error of measurement (Figure 12). This effect is caused by insufficient noise immunity of the converter and was not apparent during simulation with analogous characteristics of electronic components.

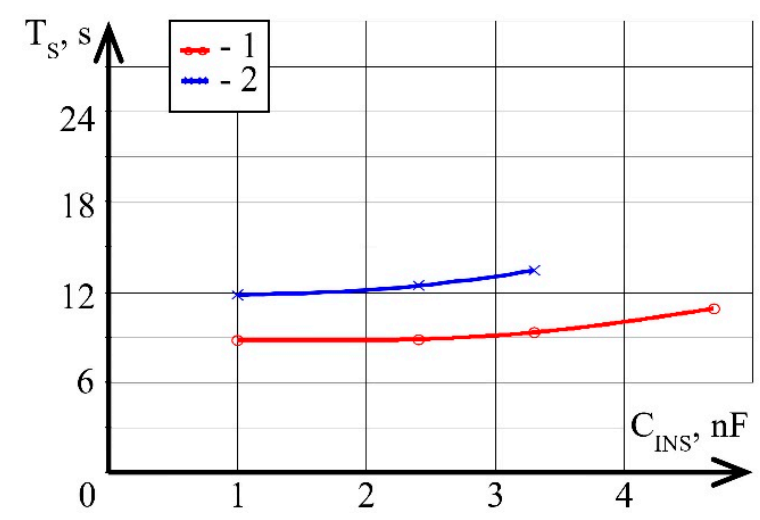

Figure 11. Experimental dependencies of the settling time during insulation resistance measurements on capacitance $C_{I N S}\left(C_{1}=1 \mathrm{nF}, U_{R E F}=100 \mathrm{~V}\right)$ when $R_{I N S}=1 \mathrm{~T} \Omega$ : 1 一the resistance-to-voltage converter with T-shaped feedback with $R_{E Q}=10 \mathrm{G} \Omega\left(R_{1}=100 \mathrm{M} \Omega, R_{2}=100 \mathrm{k} \Omega, R_{3}=1010 \Omega\right)$; 2-the resistance-to-voltage converter with a classical feedback system with $R_{E Q}=10 \mathrm{G} \Omega$.

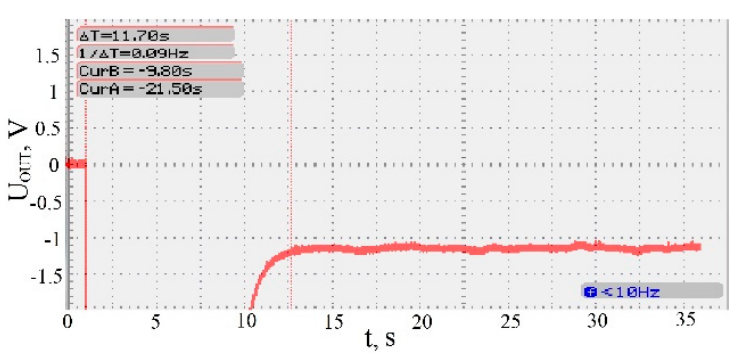

(a)

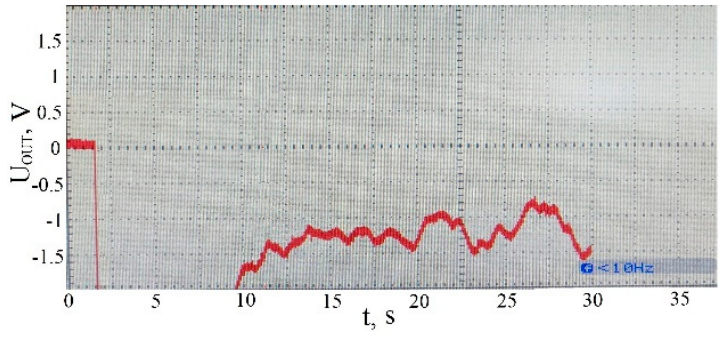

(b)

Figure 12. Oscillograms of the transient response of the output voltage of the resistance-to-voltage converter $\left(U_{R E F}=100 \mathrm{~V}\right.$, $\left.R_{E Q}=10 \mathrm{G} \Omega, R_{I N S}=1 \mathrm{~T} \Omega, C_{I N S}=10 \mathrm{nF}, C_{1}=1 \mathrm{nF}\right):(a)$ with T-shaped feedback $\left(R_{1}=100 \mathrm{M} \Omega, R_{2}=100 \mathrm{k} \Omega, R_{3}=1010 \Omega\right) ;$ (b) with a classical feedback system.

At lower ranges of measurement (10 and $100 \mathrm{G} \Omega$ ), the converter in this configuration proved to be inoperative. The capacitance $C_{1}$ value was increased to solve this problem.

Figure 13 demonstrates the experimental dependences of the settling time of resistance under measurement on capacitance $C_{I N S}$ when $C_{1}=10 \mathrm{nF}$. 


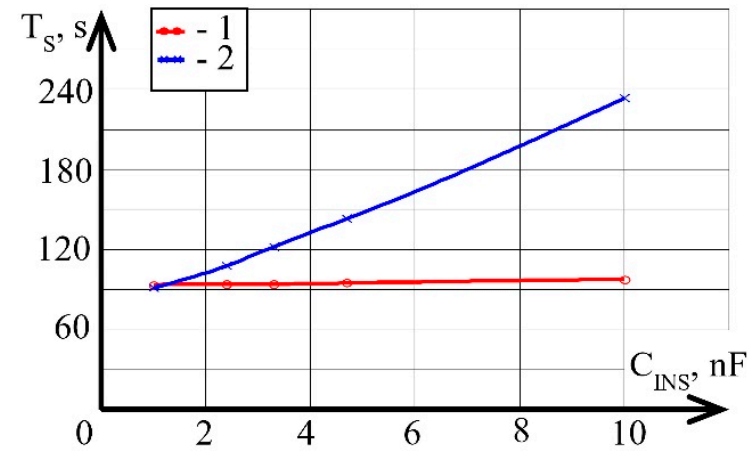

(a)

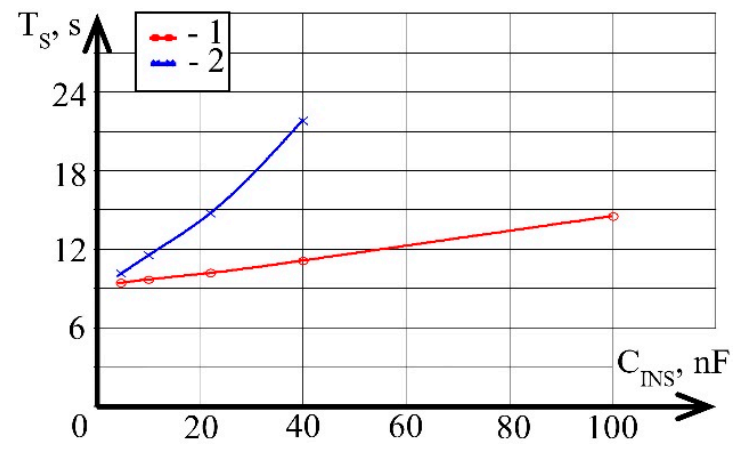

(b)

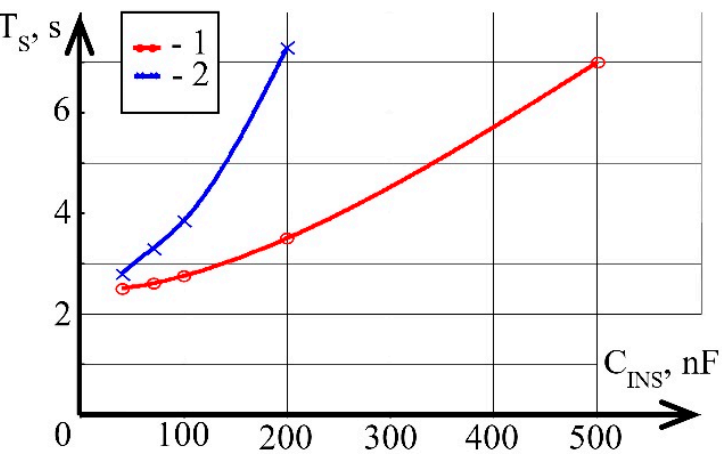

(c)

Figure 13. Experimental dependencies of the settling time during insulation resistance measurements on capacitance $C_{I N S}$ $\left(C_{1}=10 \mathrm{nF}, U_{R E F}=100 \mathrm{~V}\right)(\mathbf{a})$ when $R_{I N S}=1 \mathrm{~T} \Omega: 1$ - the resistance-to-voltage converter with T-shaped feedback with $R_{E Q}=10 \mathrm{G} \Omega\left(R_{1}=100 \mathrm{M} \Omega, R_{2}=100 \mathrm{k} \Omega, R_{3}=1010 \Omega\right) ; 2$ - the resistance-to-voltage converter with a classical feedback system with $R_{E Q}=10 \mathrm{G} \Omega$; (b) when $R_{I N S}=100 \mathrm{G} \Omega$ : 1 —the resistance-to-voltage converter with T-shaped feedback with $R_{E Q}=1 \mathrm{G} \Omega\left(R_{1}=10 \mathrm{M} \Omega, R_{2}=100 \mathrm{k} \Omega, R_{3}=1010 \Omega\right) ; 2$ - the resistance-to-voltage converter with a classical feedback system with $R_{E Q}=1 \mathrm{G} \Omega$; (c) when $R_{I N S}=10 \mathrm{G} \Omega$ : 1 —the resistance-to-voltage converter with T-shaped feedback with $R_{E Q}=0.1 \mathrm{G} \Omega\left(R_{1}=1 \mathrm{M} \Omega, R_{2}=100 \mathrm{k} \Omega, R_{3}=1010 \Omega\right) ; 2$-the resistance-to-voltage converter with a classical feedback system with $R_{E Q}=0.1 \mathrm{G} \Omega$.

At the range of measurements of resistance of $100 \mathrm{G} \Omega$ and $1 \mathrm{~T} \Omega$, the settling of the output voltage was performed monotonously without reregulating. However, during measurements of $1 \mathrm{~T} \Omega$, the settling time was more than $90 \mathrm{~s}$. In the resistance-to-voltage converter with a classical feedback system when $R_{I N S}=100 \mathrm{G} \Omega$ and $C_{I N S}$ exceeds $40 \mathrm{nF}$, spontaneous signal steps were observed, as demonstrated in Figure 12.

When $R_{I N S}=10 \mathrm{G} \Omega$, the settling of the output voltage was performed with reregulation of the transient response of more than $100 \%$. When $C_{I N S}$ exceeds $200 \mathrm{nF}$ for the resistance-to-voltage converter with a classical feedback system, and when $C_{I N S}$ exceeds $500 \mathrm{nF}$ for the resistance-to-voltage converter with T-shaped feedback, spontaneous signal steps were also observed that led to the non-operability of the converter.

Figure 14 demonstrates the experimental dependences of the settling time of resistance under measurement on capacitance $C_{I N S}$, when $C_{1}=100 \mathrm{nF}$.

At all of the ranges of measurements of resistance under study, the settling of the output voltage was performed monotonously without reregulating.

Analogously to simulation, during resistance measurements of $1 \mathrm{~T} \Omega$, the inertia of the resistance-to-voltage converter significantly increased and the settling time of the output voltage required more than $12 \mathrm{~min}$, which is not acceptable.

At the ranges of measurements of 10 and $100 \mathrm{G} \Omega$, the characteristics of dependences of the settling time on the capacitance were close to linear; these were constant and did not depend on changes of the capacitive component for the converter with T-shaped feedback within the range under study $C_{I N S}$. The resistance-to-voltage converter with T-shaped feedback demonstrated a better fast response time. 


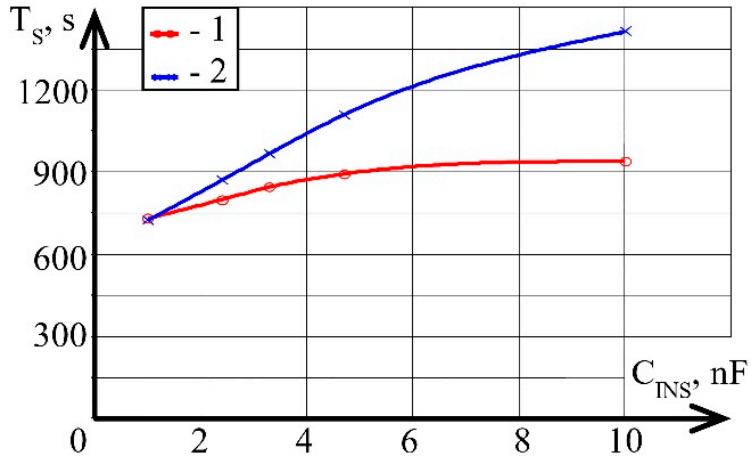

(a)

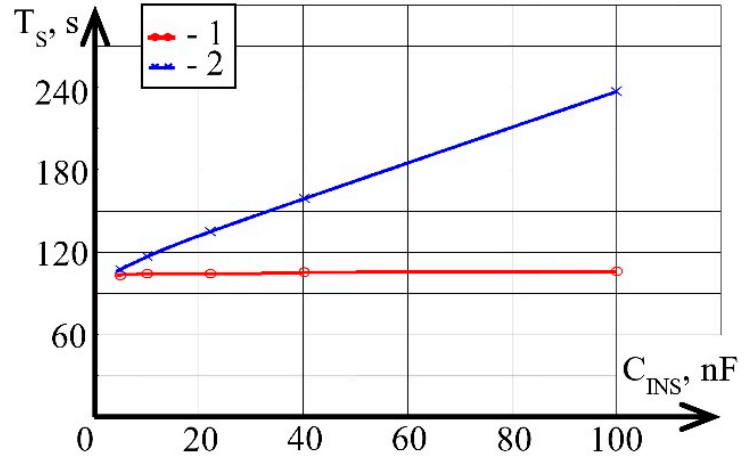

(b)

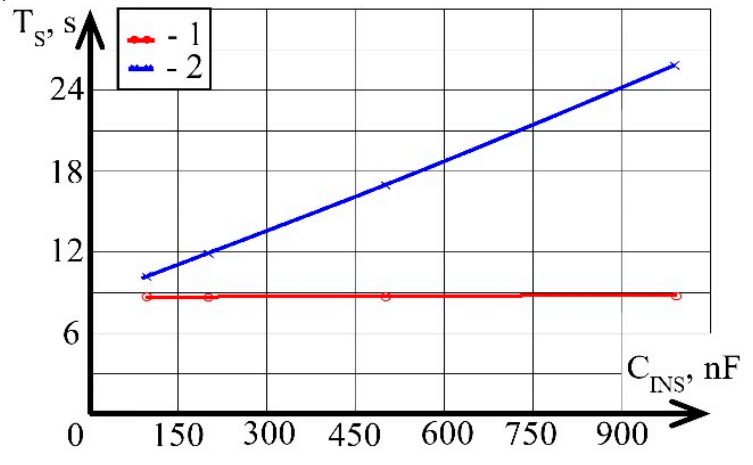

(c)

Figure 14. Experimental dependencies of the settling time during insulation resistance measurements on capacitance $C_{I N S}$ $\left(C_{1}=100 \mathrm{nF}, U_{R E F}=100 \mathrm{~V}\right)(\mathbf{a})$ when $R_{I N S}=1 \mathrm{~T} \Omega$ : 1 - the resistance-to-voltage converter with T-shaped feedback with $R_{E Q}=10 \mathrm{G} \Omega\left(R_{1}=100 \mathrm{M} \Omega, R_{2}=100 \mathrm{k} \Omega, R_{3}=1010 \Omega\right) ; 2$ - the resistance-to-voltage converter with a classical feedback system with $R_{E Q}=10 \mathrm{G} \Omega$; (b) when $R_{I N S}=100 \mathrm{G} \Omega$ : 1 一the resistance-to-voltage converter with T-shaped feedback with $R_{E Q}=1 \mathrm{G} \Omega\left(R_{1}=10 \mathrm{M} \Omega, R_{2}=100 \mathrm{k} \Omega, R_{3}=1010 \Omega\right) ; 2$-the resistance-to-voltage converter with a classical feedback system with $R_{E Q}=1 \mathrm{G} \Omega$; (c) when $R_{I N S}=10 \mathrm{G} \Omega$ : 1 -the resistance-to-voltage converter with T-shaped feedback with $R_{E Q}=0.1 \mathrm{G} \Omega$ $\left(R_{1}=1 \mathrm{M} \Omega, R_{2}=100 \mathrm{k} \Omega, R_{3}=1010 \Omega\right) ; 2$-the resistance-to-voltage converter with a classical feedback system with $R_{E Q}=0.1 \mathrm{G} \Omega$.

\subsubsection{The Usage of the Real Cable as the Object of Measurement}

PVC insulated and sheathed cable NYM-O $2 \times 1.5$ was chosen as the object of measurements (Figure 15).

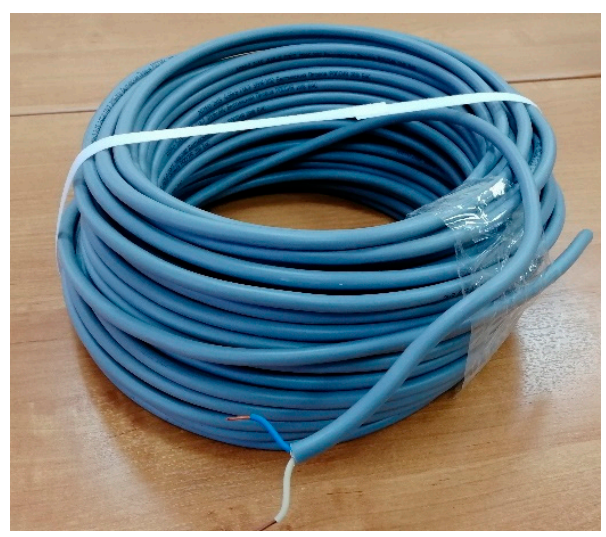

Figure 15. PVC insulated and sheathed cable NYM-O $2 \times 1.5$.

The cable possesses the following technical characteristics: length $l=50 \mathrm{~m}$, insulation resistance $R_{I N S}$ not less than $400 \mathrm{M} \Omega$, and insulation capacitance $C_{I N S}$ not exceeding $10 \mathrm{nF}$. 
The measurements were conducted in compliance with the standard [7], that is, the readings of the obtained resistance were performed after $60 \mathrm{~s}$ of applying the reference voltage $U_{R E F}$ to the cable. Figure 16 shows the oscillograms.

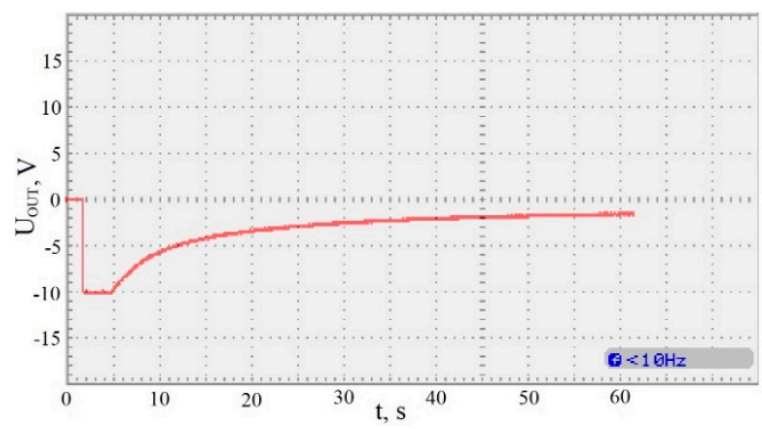

(a)

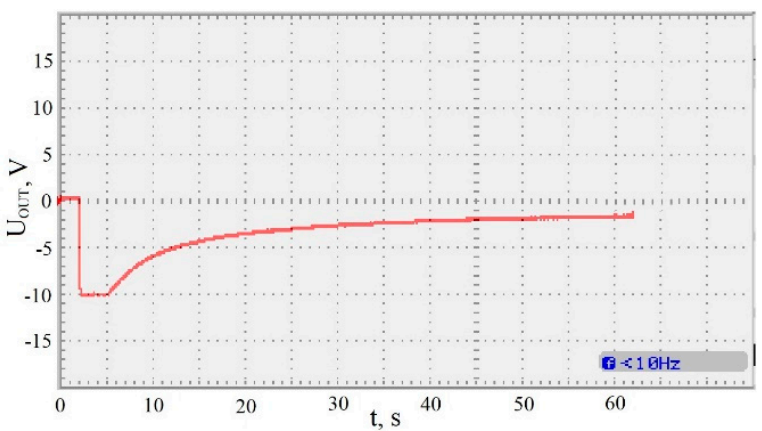

(b)

Figure 16. Oscillograms of the transient response of the output voltage of the resistance-to-voltage converter $\left(U_{R E F}=100 \mathrm{~V}\right.$, $\left.R_{E Q}=100 \mathrm{M} \Omega, C_{1}=100 \mathrm{nF}\right):(a)$ with T-shaped feedback $\left(R_{1}=1 \mathrm{M} \Omega, R_{2}=100 \mathrm{k} \Omega, R_{3}=1010 \Omega\right) ;(b)$ with a classical feedback system.

Based on the analysis of the obtained oscillograms, it was concluded that the transition processes for the converter with T-shaped feedback and for the converter with a classical feedback system are the same and in agreement with the results of theoretical modeling.

The obtained equal fast response time of the converters is explained by the very low value of the cable insulation capacitance. In Figure 14c, this corresponds to the initial line at which the effect of the fast response time is not yet significant.

The output voltage of the converters $U_{O U T}, 60 \mathrm{~s}$ after using the reference voltage $U_{R E F}$, was $-1.8 \mathrm{~V}$. According to Formula (1), the obtained cable insulation resistance was calculated and found to be equal to $5.55 \mathrm{G} \Omega$, which significantly increases its certified value.

\section{Conclusions}

From a comparison of the results of simulation with the data obtained during the experiments the following conclusions can be made:

- The characteristics of the dependencies of the settling time of the resistance under measurement on capacitance are similar to the analogous characteristics of electronic components of the resistance-to-voltage converter.

- The fast response time of the resistance-to-voltage converter with T-shaped feedback is better than that of the resistance-to-voltage converter with a classical feedback system.

- The simulation results of the fast response time of the resistance-to-voltage converter were experimentally verified. Insignificant differences of experimental results from the simulation data are caused by large departures of the components $R_{I N S}$ and $C_{I N S}$ from the nominal values.

- With minor capacitance of the object of measurement, there are no advantages in the fast response time of the resistance-to-voltage converter with T-shaped feedback in comparison to the resistance-to-voltage converter with the classical feedback system.

- There is no optimal value for the capacitance of the $C_{1}$ capacitor, for all the ranges of measurements of insulation resistance for cable products under study, simultaneously. To provide for the converter operability combined with maximum fast response time, it is necessary to change the capacitance of $C_{1}$ capacitor and the range of measurement:

(1) when $R_{E Q}=0.1 \mathrm{G} \Omega, C_{1}=100 \mathrm{nF}$;

(2) when $R_{E Q}=1 \mathrm{G} \Omega, C_{1}=10 \mathrm{nF}$;

(3) when $R_{E Q}=10 \mathrm{G} \Omega, C_{1}=1 \mathrm{nF}$.

It was experimentally proven that, with the usage of the simplified circuit of the cable substitution, the resistance-to-voltage converter with T-shaped feedback possesses a fast 
response time that is 1-3 times faster than that of the resistance-to-voltage converter with a classical feedback system.

To obtain more objective results on the fast response time of resistance-to-voltage converters during measurements of cables' insulation resistance, further investigation is needed to be performed on the premises of cable manufacturing plants to enable access to large coils of cables.

Author Contributions: Conceptualization, N.I.Y., E.V.Y. and A.E.G.; methodology, N.I.Y. and E.V.Y; validation, N.I.Y. and E.V.Y.; formal analysis, E.V.Y. and A.E.G.; investigation, N.I.Y. and E.V.Y.; data curation, A.E.G. and D.A.S.; writing—original draft preparation, N.I.Y.; writing—review and editing, E.V.Y., A.E.G. and D.A.S.; visualization, N.I.Y.; project administration, A.E.G. and D.A.S.; funding acquisition, D.A.S. All authors have read and agreed to the published version of the manuscript.

Funding: The research is carried out within the framework of Tomsk Polytechnic University Competitiveness Enhancement Program grant VIU-MNOL NK 187/2020.

Institutional Review Board Statement: Not applicable.

Informed Consent Statement: Not applicable.

Data Availability Statement: Data sharing not applicable.

Conflicts of Interest: The authors declare no conflict of interest.

\section{References}

1. $\quad$ Moore, A.B. Electric Cables Handbook, 3rd ed.; BICC Cables Ltd.: Bristol, UK, 2006; p. 1098.

2. Black, R.M. The History of Electric Wires and Cables; Peter Peregrinus Ltd.: London, UK, 1983; p. 304.

3. RG6/U Coaxial Cable. Available online: http://www.telesenner.com/otherfile/ziRaV4VMon13914.pdf (accessed on 6 December 2020).

4. 6517B Electrometer/High Resistance Meter. Available online: https://www.tek.com/datasheet/model-6517b-electrometer-high$\mathrm{r}$ (accessed on 10 July 2020).

5. Sawhney, A.K. A Course in Electrical and Electronic Measurements and Instrumentation; Dhanpat Rai \& Sons: Delhi, India, 1985; p. 1075.

6. Yermoshin, N.I.; Yakimov, E.V.; Goldshtein, A.E. Study of the effect of low-frequency interference on Resistance-to-Voltage Converter in cable insulation testing. Mater. Sci. Forum 2019, 970, 297-304. [CrossRef]

7. UL 2556 Standard for Safety. Wire and Cable Test Methods; Underwriters Laboratories Inc.: Northbrook, IL, USA, 2015.

8. Malaric, R. Instrumentation and Measurement in Electrical Engineering; BrownWalker Press: New York, NY, USA, 2011 ; p. 253.

9. Tumanski, S. Principles of Electrical Measurement; Taylor \& Francis: London, UK, 2006; p. 472.

10. Honig, R. Practical Aspects of High Resistance Measurements. Cal Lab Int. J. Metrol. 2010, 17, $22-28$.

11. Kim, K.-T.; Yu, K.-M. A new method for insulation resistance measurement at low voltage level using change of effective resistance. In Proceedings of the XIX IMECO World Congress Fundamental and Applied Metrology, Lisbon, Portugal, 6-11 September 2009; pp. 958-959.

12. Jarret, D.G. Automated guarded bridge for calibration of multimegohm standard resistor from $10 \mathrm{M} \Omega$ to $1 \mathrm{~T} \Omega$. IEEE Trans. Instrum. Meas. 1997, 46, 325-328. [CrossRef]

13. Rietveld, G.; Van der Beek, J. Active-arm resistance bridge with voltage null-detection for precision measurement of resistances above $1 \mathrm{M} \Omega$. In Proceedings of the Conference on Precision Electromagnetic Measurement (CPEM), Washington, DC, USA, 1-6 July 2012; pp. 199-200. [CrossRef]

14. Keithley Instruments. Low Level Measurements Handbook. In Precision DC Current, Voltage and Resistance Measurements, 7th ed.; Keithley Instruments Inc.: Cleveland, OH, USA, 2013; p. 245.

15. Fluke 1555 FC 10 kV Insulation Tester. Available online: https://www.fluke.com/en-gb/product/electrical-testing/insulationtesters / fluke-1555 (accessed on 19 July 2020).

16. Yakimov, E.V.; Zhukov, V.K. The Noise Immunity of Teraohmmeters Based on Current Measuring Instruments. Meas. Tech. 2003, 46, 371-376. [CrossRef]

17. Yermoshin, N.I.; Yakimov, E.V.; Goldshtein, A.E. Double-channel resistance-to-voltage converter for cable teraohmmeters. Bull. Karaganda Univ. Phys. Ser. 2020, 97, 105-114. [CrossRef]

18. Whitaker, J.C. The Electronics Handbook; Taylor \& Francis: London, UK, 2005; p. 2561.

19. Jung, W.G. Op Amp Applications Handbook; Newnes: Burlington, MA, USA, 2005; p. 895.

20. Yermoshin, N.I.; Yakimov, E.V. Feasibility of using T-shaped feedback in teraohmmeters. IOP Conf. Ser. Mater. Sci. Eng. 2018, 289, 1-6. [CrossRef]

21. Low Input Bias Current Op Amps. Available online: https://www.analog.com/en/products/amplifiers/operational-amplifiers/ low-input-bias-current-op-amps.html (accessed on 12 July 2020). 
22. Precision op Amps. Available online: https://www.ti.com/amplifier-circuit/op-amps/precision/products.html (accessed on 12 July 2020).

23. Helukabel GmbH. Selection Table for UL/CSA Cables E Wires; Helukabel: Hemmingen, Germany, $2015 ;$ p. 511.

24. Helukabel GmbH. Cables, Wires \& Accessories; Helukabel: Hemmingen, Germany, 2015; p. 76.

25. Technokabel. Cable Catalogue; Technikabel: Warszawa, Poland, 2017; p. 634.

26. Wilkens, W.D. Wire and Cable Technical Information Handbook, 3rd ed.; Anixter Inc.: Glenview, IL, USA, 1996; p. 338.

27. Wire and Cable Products. Available online: https://www.te.com/usa-en/products/wire-cable.html (accessed on 7 July 2020).

28. Vershina, H.A.; Zharin, A.L.; Tiavlovsky, A.K. Study of Static Electricity Charge Accumulation on Surface of Fluoropolymer-4 Products Using Vibrating Capacitor Method. Sci. Tech. 2012, 1, 26-32.

29. Fixed Resistors KVM, KIM, KLM. Available online: http://www.quartz1.com/price/PIC/480Q0717900.pdf (accessed on 28 July 2020).

30. Precision Polystyrene Capacitors K71-7. Available online: http://imgs.elgrad.net/Upload/sub-3/19641.pdf (accessed on 28 July 2020).

31. ADS-5304 Digital Storage Oscilloscope. Available online: http://www.aktakom.com/products/index.php?SECTION_ID=414\& ELEMENT_ID=29216 (accessed on 29 July 2020). 